\title{
The prevalence and predictors of fear of childbirth among pregnant Chinese women: a hierarchical regression analysis
}

Jingui Huang ${ }^{1}$, Jing Huang ${ }^{2}$, Yan $\mathrm{Li}^{1}$ and Bizhen Liao ${ }^{1 *}$

\begin{abstract}
Background: Fear of childbirth (FOC) occurs before, during and after pregnancy and is harmful to both the pregnant woman and the fetus. Identifying the prevalence and predictors of FOC can help us generate strategies for alleviating women's FOC.
\end{abstract}

Methods: A cross-sectional study was conducted among a convenience sample of 646 pregnant women receiving antenatal care at a subordinate hospital of a university in China. Data were collected using a basic information form, the Childbirth Attitude Questionnaire, the Childbirth Self-Efficacy Inventory, and the 10-item Connor-Davidson Resilience Scale. The minimum and maximum total scores of the Childbirth Attitude Questionnaire are 16 and 64, respectively, with higher scores reflecting a greater degree of FOC. We conducted hierarchical regression analysis to explore the predictors of FOC and used a structural equation model to further examine the direct and indirect associations between FOC, resilience and childbirth self-efficacy.

Results: The total prevalence of FOC was $67.1 \%$. The percentages of women with mild (score of 28-39), moderate (40-51), and severe FOC (52-64) were 45.4, 19.5, and 2.2\%, respectively. The average score on the Childbirth Attitude Questionnaire was 32.49, indicating mild FOC. The final regression analysis revealed six variables predicting FOC that explained $64.5 \%$ of the variance in FOC: age, gestational age, parity, spousal support, resilience, and childbirth selfefficacy. Furthermore, childbirth self-efficacy mediated the relationship between resilience and FOC, and the mediation effect rate was 53.5\%.

Conclusions: A high prevalence of FOC among pregnant Chinese women was found in this study. Age, gestational age, parity, spousal support, resilience, and childbirth self-efficacy were predictors of FOC. It is suggested that healthcare professionals should pay close attention to FOC and implement targeted interventions in accordance with these predictors, especially resilience and childbirth self-efficacy.

Keywords: Fear of childbirth, Resilience, Childbirth self-efficacy, Prevalence, Predictors

*Correspondence: 2453862566@qq.com

${ }^{1}$ Present Address: Department of Obstetrics, The First Affiliated Hospital of Chongqing Medical University, No. 1, Youyilu Street, Yuzhong District, Chongqing 400016, China

Full list of author information is available at the end of the article

\section{Background}

Fear of childbirth (FOC) is a health issue for a pregnant woman that is similar to an anxiety disorder or a phobic fear and involves physical complications, nightmares and concentration problems [1]. An increasing body of evidence suggests that FOC can affect a woman's relationship with the baby, her partner and her family [2, 3], and often results in more frequent requests for epidural 
analgesia and cesarean section [4-7]. Moreover, FOC is also related to posttraumatic stress disorder $[8,9]$ and a longer duration of labor $[7,10]$. FOC is a common psychological problem for pregnant women. Approximately $20 \%$ of gravidas experience FOC, according to existing studies [11, 12]. A meta-analysis reported a $14 \%$ pooled prevalence of FOC, but with significant heterogeneity [13]. It is normal for FOC to differ across countries considering that birth is an omnifarious experience.

Prior studies indicate that FOC is caused by multiple factors, including obstetric, sociodemographic and psychological variables. Research on the effects of obstetric factors on FOC has shown that parity [14], planned pregnancy [15] and gestational week [11] affect FOC. However, no connection was found between FOC and conception type $[16,17]$. In terms of sociodemographic factors, previous studies found that age $[18,19]$, educational level [20, 21], income level [19], and employment status $[20,21]$ are connected with FOC. Moreover, a lack of social or spousal support is connected to an increased probability of FOC $[22,23]$. Among psychological issues, childbirth self-efficacy may be linked to FOC. The higher the childbirth self-efficacy women reported was, the lower their level of FOC [24, 25].

It is worth noting that resilience, proposed and developed by positive psychology and representing one's capacity for survival and adjustment after experiencing serious traumatic events [26], can help people accommodate, handle or pass through adversity based on a selfregulating psychological mechanism [27] and recover from disasters or maintain their psychological health [28-30]. As FOC is a negative emotional experience, we speculate that resilience may have an impact on it. Additionally, research has stated that resilience influences self-efficacy [31, 32], and self-efficacy has been examined as a mediator of mental health outcomes [33]. Hence, we hypothesized that childbirth self-efficacy and resilience would have a direct effect on FOC and that resilience would have an indirect effect on FOC via childbirth self-efficacy.

This is the first study to examine the impact of resilience on FOC and the relationships among FOC, childbirth self-efficacy and resilience in pregnant women. In addition, only two studies conducted by Chinese scholars have examined the factors affecting FOC but without discussing the extent to which these variables predict FOC $[20,34]$. Taking all the reasons mentioned above into consideration, the main objective of this study is to identify the levels of FOC and evaluate the predictive factors among pregnant Chinese women and to explore the interrelationships among FOC, childbirth self-efficacy, and resilience.

\section{Methods}

\section{Design and participants}

A cross-sectional survey was conducted in the First Affiliated Hospital of Chongqing Medical University. The study was performed in accordance with the Declaration of Helsinki and was approved by the local Ethics Committee. Chongqing is a municipality located in southwestern China and has a population of approximately 31 million. The birth rate at the study hospital is more than 9000 babies per year. Pregnant women who established a health record (gestational week $\geq 11$ ) and attended routine prenatal examinations at the obstetrics clinic at the time of the research period were recruited. The inclusion criteria were Chinese pregnant women with a singleton pregnancy who were 18 years old or older, had no pregnancy complications, and had no previous cesarean section or psychiatric disorders. The exclusion criteria were women who had signs of cesarean section or declined to participate in the survey. Three well-trained researchers collected the data from August to December 2020 via a face-to-face survey. After obtaining written informed consent from participants, the researchers distributed the anonymous questionnaires and instructed them on how to fill them out. Excluding 39 respondents because of incorrect or incomplete responses and refusal, we analyzed the responses of 646 pregnant women.

\section{Measures \\ Basic information form}

The basic information form included eleven questions on respondents' age, education, occupation, marital status, residence, family per capita monthly income (RMB, renminbi, Chinese yuan), gestational age, parity, planning pregnancy, conception type, and spousal support.

\section{Fear of childbirth}

Consisting of 16 items, the Childbirth Attitude Questionnaire(CAQ) was developed to measure FOC [35]. Responses are given on a four-point Likert scale, and scores range from 16 to 64, with higher scores indicating higher FOC. The scale included four domains: fear of fetal health; fear of losing control during childbirth; fear of childbirth pain; fear of medical intervention and the hospital environment. CAQ total scores were categorized as none (16-27), mild (28-39), moderate (40-51) and severe (52-64). Wei wand her colleagues translated the scale into Chinese, and this scale has good reliability (Cronbach's $\alpha=0.91$ ) and validity (content validity index $(\mathrm{CVI})=0.924)$ [36]. Cronbach's $\alpha$ was 0.92, and the CVI was 0.930 in this study. Cronbach's $\alpha$ coefficient represents internal consistency reliability, and an $\alpha$ coefficient $\geq 0.70$ indicates acceptable reliability [37]. 


\section{Childbirth self-efficacy}

The short form of 32-item Chinese Childbirth Self-Efficacy Inventory (CBSEI-C32) was used to measure childbirth self-efficacy. The Outcome Expectancy Subscale (OE-16) and Efficacy Expectancy Subscale (EE-16) make up the CBSEI-C32 [38]. Each item is answered on a tenpoint Likert scale ranging from 1 to 10 . Total scores range from 32 to 320, and the higher scores are, the higher the self-efficacy. The Chinese version of the CBSEI-C32 has high internal consistency (Cronbach's $\alpha=0.96$ ) and testretest reliability (intraclass correlation coefficient $=0.88$ ), and significant Pearson's correlations with measures of general sense of perceived self-efficacy $(r=0.32, P<0.01)$ and anxiety $(r=-0.21, P<0.01)$ indicate its excellent construct validity [39]. The Cronbach's alpha for each subscale was 0.96 and 0.97 , and the CVI was 0.962 in this study.

\section{Resilience}

To measure resilience in pregnant Chinese women, we used the 10-item Connor-Davidson Resilience Scale (CD-RISC-10) in this study. Campbell-Sills and Stein created the original English version of the CD-RISC-10 [40]. Then, the scale was translated into Chinese and used to measure resilience in Chinese earthquake victims by Wang and his colleagues [41]. Responses are given on a four-point Likert scale, ranging from 0 ("never") to 4 ("nearly always"), with higher total scores representing better levels of resilience. The Chinese CD-RISC-10 has a Cronbach's alpha of 0.91, and significant Pearson's correlations with measures of posttraumatic stress disorder indicate its satisfactory construct validity $(r=-0.53$, $P<0.01)$ [41]. In this study, the Cronbach's alpha was 0.91 , and the CVI was 0.925 .

\section{Statistical analysis}

The mean and standard deviation (SD) were used to describe continuous variables and frequencies with percentages were used to summarize categorical variables. We performed an independent t-test and 1-way analysis of variance (ANOVA) to compare the CAQ scores between different characteristics, and Pearson correlation analyses were used to test the relationships between FOC and self-efficacy and resilience. If the above variables had a $P$ value $<0.05$ in a t-test/ANOVA or Pearson correlation analysis, they were retained in the hierarchical regression analysis model. Cook's distances $(<1.0)$ were computed to identify influential cases and outliers. The Cook's distances varied between 0.0000 and 0.08679 in this study. The Durbin-Watson (DW) statistic was used to test the independence of error terms and the sequential correlation of adjacent errors. This statistic can range from 0 to 4 , with a value of 2 indicating that the residuals are uncorrelated. The DW value was 1.900 in our study. The variance inflation factor (VIF) was applied to diagnose the possibility of multicollinearity among all the explanatory variables. A VIF less than 5 indicates that there is no serious multicollinearity. All the VIF values were $<5$ in this study. A $P$ value $<0.05$ was considered statistically significant. Data were recorded using EpiData version 3.1 after checking for completeness, and analyses were conducted using IBM SPSS Statistics version 25.

We performed structural equation modeling to analyze the mediation model. A model was established with FOC as the dependent variable, resilience as the independent variable, and childbirth self-efficacy as the mediating variable. Maximum likelihood estimation was employed as a global test of models. The bootstrapping method was used to test the significance of the indirect effect of a mediator. It is believed that an indirect effect is significant at the 0.05 level if the bias corrected 95\% confidence interval (CI) from 5000 bootstrap samples does not include 0 . Amos 23.0 was used for the modeling. The structural equation model (SEM) was acceptable with the following indexes: $x^{2} / d f<3$; root mean square error of approximation (RMSEA) $<0.08$; goodness of fit index (GFI) and adjusted goodness of fit index (AGFI) values >0.90; comparative fit index (CFI) and normed fit index (NFI) values $>0.90$; and incremental fit index (IFI) and relative fit index (RFI) values $>0.90$ [42].

\section{Results}

\section{Description of participants' basic characteristics and their} correlations with FOC

Table 1 shows the sample's sociodemographic and obstetric characteristics and their associations with the CAQ scores. The age range was 18 to 42 years, with a mean age of 28.7 ( $\mathrm{SD}=3.8$ ). Regarding sociodemographic status, $81.9 \%$ of the women had a college education and most participants were employed (82.8\%). The clear majority $(98.9 \%)$ were married and lived in cities $(91.5 \%)$. Half of the women had a family per capita monthly income of $4000-8000$ RMB (50.9\%), and the majority of the women had their partner's full support for their current pregnancy (85.8\%). In terms of the main obstetric information, the mean gestational age was 29.3 weeks and $82.4 \%$ were nulliparous.

In the univariate analysis of the factors related to the CAQ scores, seven factors were significantly related to FOC $(P<0.05)$ : age, education, marital status, gestational age, parity, pregnancy planning and spousal support. More detailed information is presented in Table 1. 
Table 1 Participants' basic characteristics and their correlations with FOC $(n=646)$

\begin{tabular}{|c|c|c|c|c|}
\hline Characteristics & N (\%) & CAQ scores (Mean $\pm \mathrm{SD}$ ) & $F$ or $t$ value & $P$ Value \\
\hline Age (years) & & & 3.324 & 0.019 \\
\hline $18-25$ & $105(16.3)$ & $33.61 \pm 9.22$ & & \\
\hline $26-30$ & $346(53.6)$ & $32.38 \pm 8.30$ & & \\
\hline $31-35$ & $156(24.1)$ & $31.24 \pm 8.32$ & & \\
\hline $36-42$ & $39(6.0)$ & $35.51 \pm 10.40$ & & \\
\hline Educational & & & 4.009 & 0.008 \\
\hline Junior middle school or below & $31(4.8)$ & $34.61 \pm 9.28$ & & \\
\hline Senior middle school or same level & $86(13.3)$ & $32.67 \pm 8.25$ & & \\
\hline University or Junior college & $460(71.2)$ & $32.80 \pm 8.56$ & & \\
\hline Master degree or above & $69(10.7)$ & $29.30 \pm 8.82$ & & \\
\hline Occupation & & & 1.590 & 0.161 \\
\hline Office clerk & $251(38.9)$ & $33.06 \pm 8.56$ & & \\
\hline Executive staff/civil servant & $36(5.6)$ & $32.28 \pm 7.63$ & & \\
\hline Medical, educational and scientific personnel & $139(21.5)$ & $31.13 \pm 8.55$ & & \\
\hline Self-employed & $39(6.0)$ & $32.15 \pm 8.63$ & & \\
\hline Other & $70(10.8)$ & $31.49 \pm 8.99$ & & \\
\hline Unemployed & $111(17.2)$ & $33.75 \pm 8.92$ & & \\
\hline Marital status & & & 2.496 & 0.013 \\
\hline Married & $639(98.9)$ & $32.41 \pm 8.60$ & & \\
\hline Other (Divorced/Separated/ Single) & $7(1.1)$ & $40.57 \pm 9.36$ & & \\
\hline Residence & & & 1.483 & 0.228 \\
\hline Urban & $591(91.5)$ & $32.46 \pm 8.62$ & & \\
\hline Town & $36(5.6)$ & $31.44 \pm 8.98$ & & \\
\hline Rural & $19(2.9)$ & $35.58 \pm 8.53$ & & \\
\hline Family per capita monthly income (RMB) & & & 0.015 & 0.985 \\
\hline$<4000$ & $54(8.4)$ & $32.31 \pm 9.17$ & & \\
\hline $4000-8000$ & $329(50.9)$ & $32.49 \pm 8.56$ & & \\
\hline$>8000$ & $263(40.7)$ & $32.54 \pm 8.67$ & & \\
\hline Gestational age (week) & & & 4.187 & 0.016 \\
\hline $11-12$ & $61(9.4)$ & $30.16 \pm 9.37$ & & \\
\hline $13-28$ & $162(25.1)$ & $31.67 \pm 8.33$ & & \\
\hline $29-40$ & $423(65.5)$ & $33.14 \pm 8.59$ & & \\
\hline Parity & & & 4.688 & 0.038 \\
\hline Nullipara & $532(82.4)$ & $33.22 \pm 8.68$ & & \\
\hline Multipara & $114(17.6)$ & $29.11 \pm 7.61$ & & \\
\hline Pregnancy planning & & & 5.523 & 0.000 \\
\hline Yes & $431(66.7)$ & $31.25 \pm 8.83$ & & \\
\hline No & $215(33.3)$ & $34.98 \pm 7.69$ & & \\
\hline Conception type & & & 0.171 & 0.864 \\
\hline Spontaneous fertilization & $613(94.9)$ & $32.51 \pm 8.63$ & & \\
\hline Assisted fertilization & $33(5.1)$ & $32.24 \pm 9.05$ & & \\
\hline Prenatal spousal support & & & 19.594 & 0.000 \\
\hline No support & $6(0.9)$ & $32.49 \pm 8.64$ & & \\
\hline Very few support & $8(1.2)$ & $43.38 \pm 11.80$ & & \\
\hline General support & $78(12.1)$ & $36.81 \pm 8.38$ & & \\
\hline Full support & $554(85.8)$ & $31.58 \pm 8.18$ & & \\
\hline
\end{tabular}


FOC levels and the correlations among FOC, self-efficacy, and resilience

The CAQ, self-efficacy, and resilience scale scores are shown in Table 2. Among a total of 646 participants, the prevalence rates of mild, moderate, and severe FOC were $45.4 \%(n=293), 19.5 \%(n=126)$, and $2.2 \%(n=14)$, respectively. The mean $\mathrm{CAQ}$ score was $32.49 \pm 8.64$. Table 2 also shows the relationship among FOC, selfefficacy and resilience. Pearson correlation analyses demonstrated that the CAQ scores were inversely related to CBSIE-32 scores, and CD-RISC-10 scores. Specifically, a positive correlation was found between the CBSIE-32 and CD-RISC-10 scores.

\section{The results of hierarchical regression analysis regarding predictors of FOC}

A three-step hierarchical regression analysis was performed to identify factors predicting FOC. The independent variables were entered as follows: step 1 included demographic and obstetric variables such as age, educational level, marital status, gestational age, parity, pregnancy planning and spousal support; step 2 included resilience variables; and step 3 included childbirth self-efficacy variables. The results of the regression analysis related to the independent variables predicting FOC are depicted in Table 3.

In the first model, obstetric and sociodemographic variables significantly explained $18.9 \%$ of the variance in FOC $(F=11.709, P<0.01)$. In the second model, the model significantly explained $49.4 \%$ of the variance in FOC with the inclusion of the CD-RISC-10 score $(F=43.888$, $P<0.01)$. In the third model, the addition of childbirth self-efficacy led to an improvement in the model, with significant changes in $\mathrm{R}^{2}$ of $15.1 \%(F=75.289, P<0.01)$. Overall, the final model explained $64.5 \%$ of the variance in FOC and revealed six variables that contributed significantly to FOC. Childbirth self-efficacy was the strongest predictor of FOC, followed by resilience. Regarding

Table 2 Scores of each scale in pregnant women and Pearson correlation coefficients $(n=646)$

\begin{tabular}{lclll}
\hline Scales & Scores (Mean \pm SD) & $\mathbf{1}$ & $\mathbf{2}$ & $\mathbf{3}$ \\
\hline 1.CAQ (range: 16-61) & $32.49 \pm 8.64$ & 1 & - & - \\
2. CBSIE-32(range: 54-320) & $201.44 \pm 58.69$ & $-0.738^{* *}$ & 1 & - \\
OE-16 (range: 26-160) & $100.38 \pm 30.02$ & $-0.711^{* *}$ & - & - \\
EE-16 (range: 23-160) & $101.05 \pm 30.01$ & $-0.732^{* *}$ & - & - \\
3. CD-RISC-10 (range: 7-40) & $26.51 \pm 5.83$ & $-0.638^{* *}$ & $0.593^{* *}$ & 1
\end{tabular}

CAQ Childbirth Attitude Questionnaire, CBSIE-32 The short form of 32-item Chinese Childbirth Self-Efficacy Inventory, CD-RISC-10 The 10-item ConnorDavidson Resilience Scale, OE-16 Outcome Expectancy Subscale, EE-16 Efficacy Expectancy Subscale, SD Standard Deviation

${ }^{* *} P<0.01$ sociodemographic variables, advanced age, late pregnancy, being nulliparous, and poor spousal support were predictors of a higher degree of FOC.

\section{Mediating effect of childbirth self-efficacy on the relation between resilience and FOC}

Figure 1 depicts the mediation models of childbirth self-efficacy and the standardized coefficients for each variable. The SEM showed significant regression and correlation paths, with all the path coefficients being statistically significant at the level of $P<0.05$. The fit indices for the model were acceptable: $x^{2} / d f=2.645$, RMSEA $=0.051$, GFI $=0.951$, AGFI $=0.932$, CFI $=0.976$, $\mathrm{NFI}=0.962$, IFI $=0.976$, and $\mathrm{RFI}=0.953$.

According to the model, FOC was significantly predicted by resilience and childbirth self-efficacy. The standardized direct effect value of childbirth self-efficacy on FOC was $-0.58(P<0.001)$, and the standardized direct effect value of resilience on FOC was $-0.33(P<0.001)$. Resilience significantly predicted childbirth self-efficacy, and the standardized direct effect of resilience on selfefficacy was $0.65(P<0.001)$. The bootstrapped 95\% CI did not include $0(-0.438 \sim-0.316, P=0.000)$, confirming that the indirect effect of resilience on FOC through childbirth self-efficacy was significant. The standardized indirect effect of resilience on FOC through self-efficacy was -0.38 . The standardized total effect of resilience on FOC was -0.71 . Therefore, indirect effects account for $53.5 \%$ of the total effect.

\section{Discussion}

The prevalence of FOC

The mean CAQ score in our study was 32.49. Comparing this mean score with those from other results, it is slightly higher than that in studies from China that used the same assessment tool (32.20 and 31.30) [20,34]. Our data showed that FOC occurred in $67 \%$ of pregnancies, and $2.2 \%$ of participants experienced severe FOC. Several studies reported the following rates of severe FOC: $5 \%$ in Australia, $5.3 \%$ in Ireland, $6.1 \%$ in Iran, $8 \%$ in Kenya, $20.8 \%$ in Turkey and $24.5 \%$ in Ethiopia [43-48]. It is difficult to compare the incidence of FOC across countries due to differences in the measures and definitions used. However, one conclusion we can draw is that FOC is a prevalent psychological problem among pregnant Chinese women, and most of them were experienced mild or moderate FOC. It is time for healthcare professionals to understand, recognize and intervene in FOC.

\section{Demographic and obstetric factors predicting FOC}

We performed hierarchical regression analysis to confirm the correlations of sociodemographic, obstetric, and other characteristics with FOC. The best-fit 
Table 3 Hierarchical regression analysis of variables in predicting FOC $(n=646)$

\begin{tabular}{|c|c|c|c|c|c|c|c|c|c|}
\hline \multirow[t]{2}{*}{ Variables } & \multicolumn{3}{|c|}{ Model 1} & \multicolumn{3}{|c|}{ Model 2} & \multicolumn{3}{|c|}{ Model 3} \\
\hline & B & $\beta$ & $P$ & B & $\beta$ & $P$ & B & $\beta$ & $P$ \\
\hline (Constant) & 37.801 & - & $<0.001$ & 58.560 & - & $<0.001$ & 62.071 & - & $<0.001$ \\
\hline \multicolumn{10}{|l|}{ Age (ref: 36-42) } \\
\hline $31-35$ & -3.159 & -.157 & .028 & -2.543 & -.126 & 0.025 & -1.900 & -.094 & .045 \\
\hline $26-30$ & -3.877 & -.224 & .005 & -3.919 & -.226 & $<0.001$ & -3.029 & -.175 & .001 \\
\hline $18-25$ & -4.159 & -.178 & .006 & -4.650 & -.199 & $<0.001$ & -3.338 & -.143 & .001 \\
\hline \multicolumn{10}{|c|}{ Educational level (ref: Junior middle school or below) } \\
\hline Senior middle school or same level & -2.530 & -.100 & .126 & -.837 & -.033 & .520 & -.157 & -.006 & .886 \\
\hline University or Junior college & -1.977 & -.105 & .185 & .272 & .014 & .819 & .167 & .009 & .867 \\
\hline Master degree or above & -4.454 & -.159 & .011 & -1.305 & -.047 & .346 & -1.405 & -.037 & .368 \\
\hline \multicolumn{10}{|l|}{ Marital status (ref: Married) } \\
\hline Other (Divorced/Separated/ Single) & 4.823 & .214 & $<0.001$ & 1.539 & .049 & .309 & 1.055 & .031 & .426 \\
\hline \multicolumn{10}{|l|}{ Gestational age (ref: 29-40) } \\
\hline $13-28$ & -1.657 & -.083 & .027 & -1.530 & -.077 & .009 & -1.292 & -.065 & .009 \\
\hline $11-12$ & -3.230 & -.109 & .003 & -2.001 & -.068 & .018 & -1.486 & -.050 & .037 \\
\hline \multicolumn{10}{|l|}{ Parity (ref: Nullipara) } \\
\hline Multipara & -5.585 & -.247 & $<0.001$ & -4.284 & -.189 & $<0.001$ & -3.502 & -.135 & $<0.001$ \\
\hline \multicolumn{10}{|l|}{ Pregnancy planning (ref: Yes) } \\
\hline No & 3.710 & .202 & $<0.001$ & 2.270 & .124 & $<0.001$ & .841 & .046 & .068 \\
\hline \multicolumn{10}{|l|}{ Spousal support (ref: Full support) } \\
\hline General support & 4.487 & .169 & $<0.001$ & 3.423 & .129 & $<0.001$ & 2.033 & .077 & .002 \\
\hline Very few support & 12.392 & .159 & $<0.001$ & 8.945 & .115 & $<0.001$ & 7.263 & .092 & $<0.001$ \\
\hline No support & 12.171 & .135 & $<0.001$ & 9.766 & .108 & $<0.001$ & 8.340 & .093 & $<0.001$ \\
\hline CD-RISC-10 & - & - & - & -.855 & -.577 & $<0.001$ & -.453 & -.305 & $<0.001$ \\
\hline CBSIE-32 ${ }^{\mathrm{a}}$ & - & - & - & - & - & - & -.073 & -.495 & $<0.001$ \\
\hline$R^{2}$ & & & 0.189 & & & 0.494 & & & 0.645 \\
\hline$R^{2}$ change & & & 0.189 & & & 0.305 & & & 0.151 \\
\hline F & & & 11.709 & & & 43.888 & & & 75.289 \\
\hline Sig. of the model & & & $<0.001$ & & & $<0.001$ & & & $<0.001$ \\
\hline
\end{tabular}

B Unstandardized coefficients, $\beta$ Standardized coefficients, ref Reference, Sig. Significance, CD-RISC-10 The 10-item Connor-Davidson Resilience Scale, CBSIE-32 The short form of 32-item Chinese Childbirth Self-Efficacy Inventory, FOC Fear of childbirth

${ }^{a}$ Continuous variable

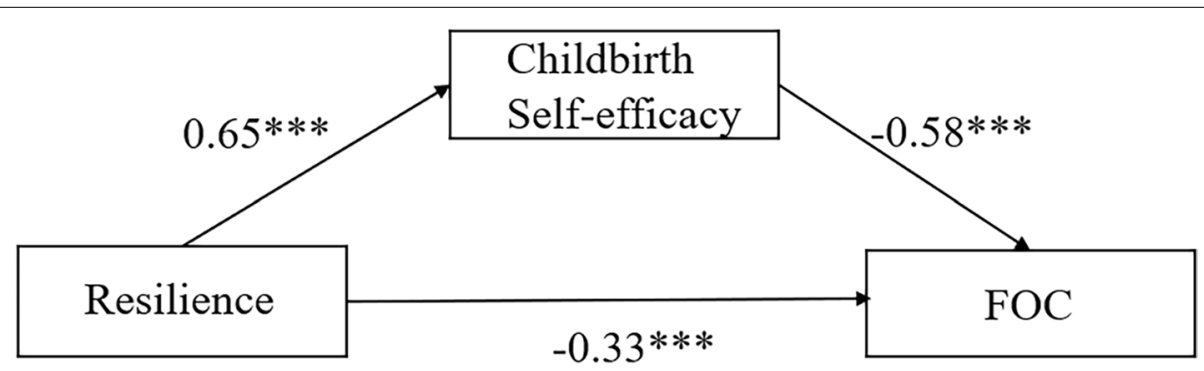

Fig. 1 The model of the mediating role of childbirth self-efficacy on the association between resilience and FOC $(n=646)$. Note: ${ }^{* *} P<0.001 ; \mathrm{FOC}$ : fear of childbirth

regression model revealed six variables that explained $64.5 \%$ of the variance in the CAQ score. Of the sociodemographic factors, advanced age was found to predict
FOC, in agreement with a previous study from Finland [19]. This may have something to do with women's belief that advanced age makes them unfit to give birth. 
However, Laursen et al. [18] demonstrated that young women $<20$ years reported intense FOC in a study from Denmark. Very young women are worried that they will not be able to take care of their child appropriately [49]. In addition, poor partner support was correlated with FOC. Similarly, previous studies showed that receiving a low level of support from one's husband increased the probability of FOC $[17,22,45]$. In Turkey, Çıtak et al. [50], in contrast to our study, found that spousal support did not predict FOC. Reproductive health at birth is considered a woman's responsibility in Turkey, so the expectation of partner support is low.

Among the obstetric features, gestational age and parity are significant predictors of FOC. As the gestational week increased, a higher level of FOC was more likely to be reported, consistent with a previous study [51]. As in other studies [51,52], multiparas had lower levels of FOC than primiparas. This is reasonable because multiparas have more experience and information about the whole delivery process [53]. However, previous work by Räisänen et al. stated that multiparous women had a higher risk of experiencing FOC [19], in which case FOC was usually related to a previous traumatic or negative childbirth experience [54, 55].

From the discussion above, we can clearly see that different studies report conflicting results regarding the association between the FOC and sociodemographic and obstetric factors. In the current study, however, the sample sources are relatively limited in terms of achieving adequate power to explore the inconsistencies surrounding this issue, and more specific research is necessary to examine their association. However, it is of great importance to design antenatal educational programs targeting for different demographic and obstetric backgrounds.

\section{Resilience}

When we added resilience to the model in the second step, the model explained $49.4 \%$ of the variance in FOC, indicating that resilience plays a significant role in predicting $\mathrm{FOC}$, a finding that has not been reported before. In terms of resilience, an increasing body of evidence suggests that resilience serves as a protective factor for psychological health and overall well-being [56, 57]. Although childbirth is a normal and healthy life experience, pregnant women with FOC may regard it as a challenge and adversity. Resilience helps individuals cope with such adversities and difficulties, so pregnant women with a better level of resilience may manage their emotions successfully, actively use their own psychological qualities to cope with the stress of childbirth, and ultimately reduce fear. In a Chinese study involving 2813 pregnant women, resilience was found to have a significant independent protective effect on prenatal anxiety/depression [58].

To the best of our knowledge, this is the first study to explore the association between resilience and FOC, providing a new perspective for developing related interventions. Health care professionals are advised to focus on resilience interventions and the formulation and implementation of programs to enhance resilience. Interventions including emotional regulation training, cognitive and behavioral therapy to reframe thoughts and refocus on positive emotions, and physical health improvement via exercise, sleep, nutrition, and mindfulness have the potential to enhance resilience [59-61]. Evidence has shown that social support or family support can provide powerful external conditions for the development of resilience [62, 63]. More specifically, higher support obtained from social networks can help pregnant women positively cope with the stressors resulting from pregnancy and childbirth. Suggested measures include encouraging husbands or other family members to provide adequate spiritual and material support for pregnant women and participate in antenatal courses and providing group activities such as peer support groups or pregnancy school to strengthen women's social interactions.

\section{Childbirth self-efficacy}

The explained variance in FOC increased to $64.5 \%$ when we included self-efficacy in the model in the third step. It is clear that childbirth self-efficacy plays an important role in predicting FOC. On the one hand, self-efficacy reflects personal beliefs about behavior that influence outcomes [64]. On the other hand, self-efficacy is the individual's confidence that they can succeed in performing that behavior in reality [65]. Women with a low level of self-efficacy may exaggerate the difficulty of a natural birth and have lower confidence in their ability to cope with the birth process. Previous studies have reflected that low self-efficacy is connected with severe FOC [47, 66]. Therefore, failing to increase their confidence in their childbirth efficacy may set women up for a distressing birth experience. Research has demonstrated positive outcomes from interventions that may be effective in increasing childbirth confidence, such as pregnancy yoga [67], mindfulness training [68], and antenatal education [69]. A New Zealand study reported that skills-based childbirth preparation contributed to an increase in mothers' self-efficacy [70]. The program included breathing exercises, verbal and nonverbal communication exercises, tension-reducing exercises, and body exercises as well as advice about stages, delivery methods, and when to use certain skills.

Another interesting finding of this study is that we found a mediating effect of childbirth self-efficacy on 
the relationship between resilience and FOC. In other words, a better level of resilience brought out stronger self-efficacy, which in turn reduced the CAQ score. The mediation effect rate was $53.5 \%$, confirming that resilience indirectly acted on FOC through self-efficacy. The reason may be that pregnant women with higher resilience make fuller use of their psychological resources to arouse and strengthen their mental capacity to accept the birth event and reevaluate it, and this in turn is beneficial in giving them greater confidence regarding childbirth, thus reducing fear. The mediating effect of childbirth selfefficacy on resilience and FOC found through an SEM provided new insight into those factors influencing FOC. This finding showed that preventive interventions aimed at enhancing resilience and self-efficacy may be conducive to effectively alleviating pregnant women's fear.

\section{Conclusions}

In sum, we found a high prevalence of FOC among pregnant women in China. Health care professionals should attach importance to FOC and address this issue thoroughly. Age, gestational age, parity, spousal support, resilience and childbirth self-efficacy are predictors of FOC. The findings help us to identify the characteristics of patients with FOC and to formulate corresponding countermeasures. Another point to note is that interventions focusing on enhancing resilience and self-efficacy may alleviate FOC. To provide favorable external conditions for the development of resilience, it is necessary for antenatal care providers to offer timely support to pregnant women through psychological counseling and create peer support groups that allow women to share their fears, experiences and stories and techniques for coping with labor pain. In addition, health care professionals should attach importance to cultivating women's childbirth self-efficacy via various channels, such as strengthening prenatal education, offering pregnancy yoga courses, and organizing companion-integrated childbirth preparation [24].

\section{Strengths and limitations}

This study has several strengths. First, it has shed light on the relation between resilience and FOC, as there are no relevant studies on this topic. Second, we used an SEM and found a mediating effect of childbirth selfefficacy on the relationship between resilience and FOC, which may provide valuable information for health care professionals.

Regarding limitations, first, this study was conducted in a university-affiliated hospital in a large urban area, which may not allow the current results to represent all pregnant Chinese women. Further research should focus on women in rural and remote communities. Second, because this study was cross-sectional, conclusions about the causal relation between FOC and related factors could not be derived. Thus, future prospective studies are needed.

\section{Abbreviations}

FOC: Fear of childbirth; CAQ: Childbirth Attitude Questionnaire; CBSEI-C32: The short form of 32-item Chinese Childbirth Self-Efficacy Inventory; CD-RISC-10:

The 10-item Connor-Davidson Resilience Scale; OE: Outcome Expectancy Subscale; EE: Efficacy Expectancy Subscale; RMB: Renminbi; CVI: Content validity index; SD: Standard deviation; ANOVA: Analysis of variance; DW: Durbin-Watson; VIF: Variance inflation factor; SEM: Structural equation model; Cl: Confidence interval; RMSEA: Root mean square error of approximation; GFI: Goodness of fit index; AGFI: Adjusted goodness of fit index; CFI: Comparative fit index; NFI: Normed fit index; IFl: Incremental fit index; RFI: Relative fit index.

\section{Acknowledgements}

Our appreciation goes to all the pregnant women who participated in this study.

\section{Authors' contributions}

JG H conceptualized and designed the study, collected the data, logged and analyzed the data, and drafted the manuscript. JH participated in the study design, collected the data, and checked the data. YL contributed to data acquisition, read the entire manuscript critically and proposed suggestions on revision. $B Z L$ was responsible for the conception and revision. All authors read and approved the final manuscript.

Funding

This study received no funding.

Availability of data and materials

The datasets used and/or analysed during the current study are available from the corresponding author on reasonable request.

\section{Declarations}

\section{Ethics approval and consent to participate}

The study meets the ethical guidelines of the Helsinki Declaration, and the protocol was approved by the Ethics Committee of the First Affiliated Hospital of Chongqing Medical University (2020-478). Written informed consent was obtained from participants prior to their participation in the study.

\section{Consent for publication}

Not applicable.

\section{Competing interests}

The authors declare that they have no competing interests.

\section{Author details}

1Present Address: Department of Obstetrics, The First Affiliated Hospital of Chongqing Medical University, No. 1, Youyilu Street, Yuzhong District, Chongqing 400016, China. ${ }^{2}$ Department of Endocrinology, The First Affiliated Hospital of Chongqing Medical University, Chongqing 400016, China.

Received: 7 March 2021 Accepted: 15 September 2021

Published online: 22 September 2021

References

1. Saisto T, Halmesmäki E. Fear of childbirth: a neglected dilemma. Acta Obstet Gynecol Scand. 2003;82(3):201-8.

2. Challacombe FL, Nath S, Trevillion K, Pawlby S, Howard LM. Fear of childbirth during pregnancy: associations with observed mother-infant interactions and perceived bonding. Arch Womens Ment Health. 2020. https://doi.org/10.1007/s00737-020-01098-w. 
3. Wijma K. Why focus on 'fear of childbirth'? J Psychosom Obstet Gynaecol. 2003;24(3):141-3. https://doi.org/10.3109/01674820309039667.

4. Preis $\mathrm{H}$, Benyamini Y, Eberhard-Gran M, Garthus-Niegel S. Childbirth preferences and related fears - comparison between Norway and Israel. BMC Pregnancy Childbirth. 2018;18(1):362. https://doi.org/10.1186/ s12884-018-1997-5.

5. Sluijs AM, Wijma K, Cleiren M, van Lith JMM, Wijma B. Preferred and actual mode of delivery in relation to fear of childbirth. J Psychosom Obstet Gynaecol. 2020;41(4):266-74. https://doi.org/10.1080/0167482x.2019. 1708319.

6. Stützer PP, Berlit S, Lis S, Schmahl C, Sütterlin M, Tuschy B. Elective Caesarean section on maternal request in Germany: factors affecting decision making concerning mode of delivery. Arch Gynecol Obstet. 2017;295(5):1151-6. https://doi.org/10.1007/s00404-017-4349-1.

7. Adams SS, Eberhard-Gran M, Eskild A. Fear of childbirth and duration of labour: a study of 2206 women with intended vaginal delivery. BJOG. 2012;1 19(10):1238-46. https://doi.org/10.1111/j.1471-0528.2012.03433.x.

8. Söderquist J, Wijma K, Wijma B. Traumatic stress in late pregnancy. J Anxiety Disord. 2004;18(2):127-42. https://doi.org/10.1016/s0887-6185(02) 00242-6.

9. Çapik A, Durmaz H. Fear of childbirth, postpartum depression, and birth-related variables as predictors of posttraumatic stress disorder after childbirth. Worldviews Evid Based Nurs. 2018;15(6):455-63. https://doi. org/10.1111/wvn.12326.

10. Sydsjö G, Angerbjörn L, Palmquist S, Bladh M, Sydsjö A, Josefsson A. Secondary fear of childbirth prolongs the time to subsequent delivery. Acta Obstet Gynecol Scand. 2013;92(2):210-4. https://doi.org/10.1111/aogs. 12034.

11. Hildingsson I, Haines $H$, Karlström A, Nystedt A. Presence and process of fear of birth during pregnancy-findings from a longitudinal cohort study. Women Birth. 2017;30(5):e242-7. https://doi.org/10.1016/j.wombi.2017. 02.003 .

12. Poggi L, Goutaudier N, Séjourné N, Chabrol H. When fear of childbirth is pathological: the fear continuum. Matern Child Health J. 2018;22(5):7728. https://doi.org/10.1007/s10995-018-2447-8.

13. O'Connell MA, Leahy-Warren P, Khashan AS, Kenny LC, O'Neill SM. Worldwide prevalence of tocophobia in pregnant women: systematic review and meta-analysis. Acta Obstet Gynecol Scand. 2017;96(8):907-20. https://doi.org/10.1111/aogs.13138

14. Spice K, Jones SL, Hadjistavropoulos HD, Kowalyk K, Stewart SH. Prenatal fear of childbirth and anxiety sensitivity. J Psychosom Obstet Gynaecol. 2009:30(3):168-74. https://doi.org/10.1080/01674820902950538.

15. Phunyammalee $M$, Buayaem T, Boriboonhirunsarn D. Fear of childbirth and associated factors among low-risk pregnant women. J Obstet Gynaecol. 2019;39(6):763-7. https://doi.org/10.1080/01443615.2019.1584885.

16. Poikkeus P, Saisto T, Unkila-Kallio L, Punamaki RL, Repokari L, Vilska S, et al. Fear of childbirth and pregnancy-related anxiety in women conceiving with assisted reproduction. Obstet Gynecol. 2006;108(1):70-6. https://doi. org/10.1097/01.AOG.0000222902.37120.2f

17. Molgora S, Fenaroli V, Prino LE, Rollè L, Sechi C, Trovato A, et al. Fear of childbirth in primiparous Italian pregnant women: the role of anxiety, depression, and couple adjustment. Women Birth. 2018;31(2):117-23. https://doi.org/10.1016/j.wombi.2017.06.022

18. Laursen $M$, Hedegaard M, Johansen C. Fear of childbirth: predictors and temporal changes among nulliparous women in the Danish National Birth Cohort. BJOG. 2008;115(3):354-60. https://doi.org/10.1111/j.14710528.2007.01583.x

19. Räisänen S, Lehto SM, Nielsen HS, Gissler M, Kramer MR, Heinonen S Fear of childbirth in nulliparous and multiparous women: a populationbased analysis of all singleton births in Finland in 1997-2010. BJOG. 2014;121 (8):965-70. https://doi.org/10.1111/1471-0528.12599.

20. Qiu L, Sun N, Shi X, Zhao Y, Feng L, Gong Y, et al. Fear of childbirth in nulliparous women: a cross-sectional multicentre study in China. Women Birth. 2020;33(2):e136-41. https://doi.org/10.1016/j.wombi.2019.04.005.

21. Khwepeya M, Lee GT, Chen SR, Kuo SY. Childbirth fear and related factors among pregnant and postpartum women in Malawi. BMC Pregnancy Childbirth. 2018;18(1):391. https://doi.org/10.1186/s12884-018-2023-7.

22. Saisto T, Salmela-Aro K, Nurmi JE, Halmesmäki E. Psychosocial characteristics of women and their partners fearing vaginal childbirth. BJOG. 2001;108(5):492-8. https://doi.org/10.1111/j.1471-0528.2001.00122.x.
23. Fisher C, Hauck Y, Fenwick J. How social context impacts on women's fears of childbirth: a Western Australian example. Soc Sci Med. 2006;63(1):64-75. https://doi.org/10.1016/j.socscimed.2005.11.065.

24. Munkhondya BMJ, Munkhondya TE, Chirwa E, Wang H. Efficacy of companion-integrated childbirth preparation for childbirth fear, self-efficacy, and maternal support in primigravid women in Malawi. BMC Pregnancy Childbirth. 2020:20(1):48. https://doi.org/10.1186/s12884-019-2717-5.

25. Salomonsson B, Gullberg MT, Alehagen S, Wijma K. Self-efficacy beliefs and fear of childbirth in nulliparous women. J Psychosom Obstet Gynaecol. 2013;34(3):116-21. https://doi.org/10.3109/0167482×.2013.824418.

26. Rutter M. Resilience in the face of adversity. Protective factors and resistance to psychiatric disorder. Br J Psychiatry. 1985;147:598-611. https:// doi.org/10.1192/bjp.147.6.598.

27. Ye ZJ, Guan HJ, Wu LH, Xiao MY, Luo DM, Quan XM. Resilience and psychosocial function among Mainland Chinese parents of children with cancer: a cross-sectional survey. Cancer Nurs. 2015;38(6):466-74. https:// doi.org/10.1097/ncc.0000000000000220.

28. Okuyama J, Funakoshi S, Tomita H, Yamaguchi T, Matsuoka H. Longitudinal characteristics of resilience among adolescents: a high school student cohort study to assess the psychological impact of the Great East Japan Earthquake. Psychiatry Clin Neurosci. 2018;72(11):821-35. https://doi.org/ 10.1111/pcn.12772.

29. Ungar M, Theron L. Resilience and mental health: how multisystemic processes contribute to positive outcomes. Lancet Psychiatry. 2020;7(5):4418. https://doi.org/10.1016/s2215-0366(19)30434-1.

30. Southwick SM, Charney DS. The science of resilience: implications for the prevention and treatment of depression. Science. 2012;338(6103):79-82. https://doi.org/10.1126/science.1222942.

31. Yang C, Zhou Y, Cao Q, Xia M, An J. The relationship between self-control and self-efficacy among patients with substance use disorders: resilience and self-esteem as mediators. Front Psychiatry. 2019;10:388. https://doi. org/10.3389/fpsyt.2019.00388.

32. Etherton K, Steele-Johnson D, Salvano K, Kovacs N. Resilience effects on student performance and well-being: the role of self-efficacy, self-set goals, and anxiety. J Gen Psychol. 2020:1-20. https://doi.org/10.1080/ 00221309.2020 .1835800$.

33. Jia Y, Shi J, Sznajder KK, Yang F, Cui C, Zhang W, et al. Positive effects of resilience and self-efficacy on World Health Organization Quality of Life Instrument score among caregivers of stroke inpatients in China. Psychogeriatrics. 2021;21(1):89-99. https://doi.org/10.1111/psyg.12635.

34. Gao LL, Liu XJ, Fu BL, Xie W. Predictors of childbirth fear among pregnant Chinese women: a cross-sectional questionnaire survey. Midwifery. 2015;31(9):865-70. https://doi.org/10.1016/j.midw.2015.05.003.

35. Lowe NK. Self-efficacy for labor and childbirth fears in nulliparous pregnant women. J Psychosom Obstet Gynaecol. 2000;21(4):219-24. https:// doi.org/10.3109/01674820009085591.

36. Wei J, Liu J, Zhang L, Wu Y, Fu C. Reliability and validity of the Chinese version of Childbirth Attitudes Questionnaire. J Nurs. 2016;31(02):81-3.

37. Bates TA, Clark PC. Reliability and validity of the simulation learning effectiveness inventory. J Prof Nurs. 2019;35(6):461-6. https://doi.org/10. 1016/j.profnurs.2019.04.007.

38. Ip WY, Chung TK, Tang CS. The Chinese Childbirth Self-Efficacy Inventory: the development of a short form. J Clin Nurs. 2008;17(3):333-40. https:// doi.org/10.1111/j.1365-2702.2006.01919.x.

39. Gao LL, Ip WY, Sun K. Validation of the short form of the Chinese Childbirth Self-Efficacy Inventory in Mainland China. Res Nurs Health. 2011;34(1):49-59. https://doi.org/10.1002/nur.20400.

40. Campbell-Sills L, Stein MB. Psychometric analysis and refinement of the Connor-davidson Resilience Scale (CD-RISC): validation of a 10-item measure of resilience. J Trauma Stress. 2007;20(6):1019-28. https://doi. org/10.1002/jts.20271.

41. Wang L, Shi Z, Zhang Y, Zhang Z. Psychometric properties of the 10-item Connor-Davidson Resilience Scale in Chinese earthquake victims. Psychiatry Clin Neurosci. 2010;64(5):499-504. https://doi.org/10.1111/j. 1440-1819.2010.02130.x.

42. Chiao HM, Chen YL, Huang WH. Data on the acceptance of a tourism navigation system applying structuring equation modeling analysis. Data Brief. 2018;20:1392-6. https://doi.org/10.1016/j.dib.2018.09.002.

43. Pallant JF, Haines HM, Green P, Toohill J, Gamble J, Creedy DK, et al. Assessment of the dimensionality of the Wijma delivery expectancy/experience 
questionnaire using factor analysis and Rasch analysis. BMC Pregnancy Childbirth. 2016;16(1):361. https://doi.org/10.1186/s12884-016-1157-8.

44. O'Connell MA, Leahy-Warren P, Kenny LC, O'Neill SM, Khashan AS. The prevalence and risk factors of fear of childbirth among pregnant women: a cross-sectional study in Ireland. Acta Obstet Gynecol Scand. 2019;98(8):1014-23. https://doi.org/10.1111/aogs.13599.

45. Mortazavi F, Agah J. Childbirth fear and associated factors in a sample of pregnant Iranian women. Oman Med J. 2018;33(6):497-505. https://doi. org/10.5001/omj.2018.91.

46. Onchonga D, MoghaddamHosseini V, Keraka M, Várnagy Á. Prevalence of fear of childbirth in a sample of gravida women in Kenya. Sex Reprod Healthc. 2020;24:100510. https://doi.org/10.1016/j.srhc.2020.100510.

47. Çıtak Bilgin N, Coşkun H, Coşkuner Potur D, Ibar Aydın E, Uca E. Psychosocial predictors of the fear of childbirth in Turkish pregnant women. J Psychosom Obstet Gynaecol. 2020:1-9. https://doi.org/10.1080/01674 82x.2020.1734791.

48. Gelaw T, Ketema TG, Beyene K, Gurara MK, Ukke GG. Fear of childbirth among pregnant women attending antenatal care in Arba Minch town, southern Ethiopia: a cross-sectional study. BMC Pregnancy Childbirth. 2020:20(1):672. https://doi.org/10.1186/s12884-020-03367-z.

49. YoosefiLebni J, KhalajabadiFarahani F, Solhi M, EbadiFard Azar F. Causes and grounds of childbirth fear and coping strategies used by Kurdish adolescent pregnant women in Iran: a qualitative study. J Reprod Infertil. 2021;22(1):47-56. https://doi.org/10.18502/jri.v22i1.4995.

50. ÇıtakBilgin N, Coşkun H, CoşkunerPotur D, Ibar Aydın E, Uca E. Psychosocial predictors of the fear of childbirth in Turkish pregnant women. $J$ Psychosom Obstet Gynaecol. 2021;42(2):123-31. https://doi.org/10.1080/ 0167482x.2020.1734791.

51. Rouhe H, Salmela-Aro K, Halmesmäki E, Saisto T. Fear of childbirth according to parity, gestational age, and obstetric history. BJOG. 2009;116(1):6773. https://doi.org/10.1111/j.1471-0528.2008.02002.x.

52. Serçekuş P, Vardar O, Özkan S. Fear of childbirth among pregnant women and their partners in Turkey. Sex Reprod Healthc. 2020;24:100501. https:// doi.org/10.1016/j.srhc.2020.100501.

53. Soltani F, Eskandari Z, Khodakarami B, Parsa P, Roshanaei G. Factors contributing to fear of childbirth among pregnant women in Hamadan (Iran) in 2016. Electron Physician. 2017;9(7):4725-31. https://doi.org/10.19082/ 4725.

54. Handelzalts JE, Becker G, Ahren MP, Lurie S, Raz N, Tamir Z, et al. Personality, fear of childbirth and birth outcomes in nulliparous women. Arch Gynecol Obstet. 2015;291(5):1055-62. https://doi.org/10.1007/ s00404-014-3532-x.

55. Nilsson C, Hessman E, Sjöblom H, Dencker A, Jangsten E, Mollberg M, et al. Definitions, measurements and prevalence of fear of childbirth: a systematic review. BMC Pregnancy Childbirth. 2018;18(1):28. https://doi. org/10.1186/s12884-018-1659-7.

56. Sheerin CM, Lind MJ, Brown EA, Gardner CO, Kendler KS, Amstadter AB. The impact of resilience and subsequent stressful life events on MDD and GAD. Depress Anxiety. 2018;35(2):140-7. https://doi.org/10.1002/da. 22700.

57. Zhang L, Yang X, Zhao J, Zhang W, Cui C, Yang F, et al. Prevalence of prenatal depression among pregnant women and the importance of resilience: a multi-site questionnaire-based survey in Mainland China. Front Psychiatry. 2020;11:374. https://doi.org/10.3389/fpsyt.2020.00374.
58. Ma $X$, Wang $Y$, Hu H, Tao $X G$, Zhang $Y$, Shi $H$. The impact of resilience on prenatal anxiety and depression among pregnant women in Shanghai. J Affect Disord. 2019;250:57-64. https://doi.org/10.1016/j.jad.2019.02.058.

59. Chandler GE, Roberts SJ, Chiodo L. Resilience intervention for young adults with adverse childhood experiences. J Am Psychiatr Nurses Assoc. 2015;21 (6):406-16. https://doi.org/10.1177/1078390315620609.

60. Bellis MA, Hardcastle K, Ford K, Hughes K, Ashton K, Quigg Z, et al. Does continuous trusted adult support in childhood impart life-course resilience against adverse childhood experiences - a retrospective study on adult health-harming behaviours and mental well-being. BMC Psychiatry. 2017;17(1):110. https://doi.org/10.1186/s12888-017-1260-z.

61. Adler AB, Williams J, McGurk D, Moss A, Bliese PD. Resilience training with soldiers during basic combat training: randomisation by platoon. Appl Psychol Health Well Being. 2015;7(1):85-107. https://doi.org/10.1111/ aphw.12040.

62. Kong LN, Zhang N, Yuan C, Yu ZY, Yuan W, Zhang GL. Relationship of social support and health-related quality of life among migrant older adults: the mediating role of psychological resilience. Geriatr Nurs. 2021;42(1):1-7. https://doi.org/10.1016/j.gerinurse.2020.10.019.

63. Xu Y, Lin X, Chen S, Liu Y, Liu H. Ageism, resilience, coping, family support, and quality of life among older people living with HIV/AIDS in Nanning. China Glob Public Health. 2018;13(5):612-25. https://doi.org/10.1080/ 17441692.2016.1240822.

64. Bandura A. Self-efficacy: toward a unifying theory of behavioral change. Psychol Rev. 1977;84(2):191-215. https://doi.org/10.1037//0033-295x. 84.2.191.

65. Lowe NK. Maternal confidence for labor: development of the Childbirth Self-Efficacy Inventory. Res Nurs Health. 1993;16(2):141-9. https://doi.org/ 10.1002/nur.4770160209.

66. Schwartz L, Toohill J, Creedy DK, Baird K, Gamble J, Fenwick J. Factors associated with childbirth self-efficacy in Australian childbearing women. BMC Pregnancy Childbirth. 2015;15:29. https://doi.org/10.1186/ s12884-015-0465-8.

67. Campbell VR, Nolan M. A qualitative study exploring how the aims, language and actions of yoga for pregnancy teachers may impact upon women's self-efficacy for labour and birth. Women Birth. 2016;29(1):3-11. https://doi.org/10.1016/j.wombi.2015.04.007.

68. Duncan LG, Cohn MA, Chao MT, Cook JG, Riccobono J, Bardacke N. Benefits of preparing for childbirth with mindfulness training: a randomized controlled trial with active comparison. BMC Pregnancy Childbirth. 2017;17(1):140. https://doi.org/10.1186/s12884-017-1319-3.

69. Serçekus P, Başkale H. Effects of antenatal education on fear of childbirth, maternal self-efficacy and parental attachment. Midwifery. 2016;34:16672. https://doi.org/10.1016/j.midw.2015.11.016.

70. Howarth AM, Swain NR. Skills-based childbirth preparation increases childbirth self-efficacy for first time mothers. Midwifery. 2019;70:100-5. https://doi.org/10.1016/j.midw.2018.12.017.

\section{Publisher's Note}

Springer Nature remains neutral with regard to jurisdictional claims in published maps and institutional affiliations.

Ready to submit your research? Choose BMC and benefit from

- fast, convenient online submission

- thorough peer review by experienced researchers in your field

- rapid publication on acceptance

- support for research data, including large and complex data types

- gold Open Access which fosters wider collaboration and increased citations

- maximum visibility for your research: over $100 \mathrm{M}$ website views per year

At BMC, research is always in progress.

Learn more biomedcentral.com/submissions 